J. Clin. Chem. Clin. Biochem.

Vol. 27, 1989, pp. 3-12

(C) 1989 Walter de Gruyter \& Co.

Berlin · New York

\title{
Platelet-Modified Low Density Lipoprotein Induces Macrophage Cholesterol Accumulation and Platelet Activation
}

\author{
By Michael Aviram, Bianca Fuhrman, Shlomo Keidar, Irit Maor, Mira Rosenblat, Gertrude Dankner and Gerald \\ Brook
}

Lipid Research Unit, Rambam Medical Center and

Rappoport Family Institute for Research in Medical Sciences

Technion - Israel Institute of Technology, Haifa, Israel

(Received June 14/October 19, 1988)

\begin{abstract}
Summary: Low density lipoprotein (LDL), modified by chemical or biological means, was shown to induce macrophage cholesterol accumulation. The cholesterol and protein contents of LDL were decreased (by 10 and $15 \%$, respectively) by incubation of the LDL for $2 \mathrm{~h}$ at $37{ }^{\circ} \mathrm{C}$ with normal washed platelet suspension or with platelet-conditioned medium; these decreases were not affected by platelet activation. The plateletmodified LDL caused a greater increase (by up to $15 \%$ ) in collagen-induced, in vitro platelet aggregation than control LDL. Incubation of mouse peritoneal macrophages with platelet-modified LDL for $18 \mathrm{~h}$ at $37^{\circ} \mathrm{C}$ resulted in an elevation of the macrophage cholesterol ester content (by $35-50 \%$ ) as well as an increase in the cholesterol esterification rate (by $40-70 \%$ ), compared with the effect of control LDL. Macrophage cholesterol synthesis, however, was significantly decreased (by $40-50 \%$ ), compared with the effect of control LDL. The effect of LDL treated by platelet-conditioned medium was similar to that of platelet-modified LDL. The effect of platelet-modified LDL on macrophage cholesterol esterification was maximal within $24 \mathrm{~h}$ of incubation, and it was not significantly affected by inhibition of cholesterol synthesis. The platelet-modified LDL was taken up by the macrophages in a saturable fashion and its uptake was competitively inhibited by LDL, but not by acetylated LDL. We conclude that platelet-modified LDL interacts with the LDL receptor and induces macrophage cholesterol accumulation. Since the modified lipoprotein induces in vitro foam cell formation and platelet activation, platelet-modified LDL could be considered to be pro-atherogenic.
\end{abstract}

\section{Introduction}

Macrophage cholesterol accumulation is a prominent early characteristic of the atherosclerotic lesion (1). Plasma lipoproteins modified in vitro, either chemically by acetylation, or biologically by endothelial or smooth muscle cells, have been shown to cause macrophage cholesterol accumulation $(1-3)$. Cholesterol accumulation in macrophages after incubation with modified low density lipoprotein (LDL) is the result of lipoprotein interaction with specific receptors which differ from the native LDL receptor (4). After receptor-mediated endocytosis, the lipoprotein is transferred to the lysosomal compartment, where the cholesterol ester is hydrolysed to free cholesterol by acid lipase and then transferred to the cytoplasm. In the cytoplasm, the free cholesterol is esterified by acyl coenzyme A cholesterol acyltransferase or transferred to the plasma membrane, where it can be removed by cholesterol acceptors such as high density lipoprotein. The influx of cholesterol into the macrophages results in inhibition of cellular cholesterol synthesis and thus, in the regulation of the cellular cholesterol content.

Modified lipoprotein causes the accumulation of cholesterol ester in macrophages, thus leading to foam cell formation $(1-3)$. Since platelets are involved in 
the atherosclerotic process (5) and interact with plasma lipoproteins (6), with the vessel wall and with macrophages (7), platelet-modified LDL, if formed in vivo, may be of importance in the pathogenesis of atherosclerosis. Recently we have shown that platelets can modify LDL composition in vitro (8). The present study was undertaken in order to study the biological characteristics of platelet-modified LDL formed in vitro, in two distinct mechanisms involved in the atherogenic process: macrophage cholesterol accumulation and platelet activation.

\section{Methods}

\section{Platelet preparation}

Venous blood was collected after a $14 \mathrm{~h}$ fast from healthy subjects who bad taken no medication for at least 3 weeks preceding the study. Blood was taken into acid citrate dextrose ( $2.5 \mathrm{~g} / \mathrm{l}$ citric acid, $25 \mathrm{~g} / \mathrm{l}$ sodium citrate, and $20 \mathrm{~g} / \mathrm{l}$ dextrose) in a $6: 1$ volume ratio. Platelet-rich plasma was prepared by low-speed centrifugation at $200 \mathrm{~g}$ for $10 \mathrm{~min}$ at $23^{\circ} \mathrm{C}$. Washed platelets were prepared from the platelet-rich plasma. Acetic acid $(10 \mathrm{mmol} / \mathrm{l})$ was added to the platelet-rich plasma, which was then centrifuged at $1500 \mathrm{~g}$ for $10 \mathrm{~min}$. The supernatant was removed and the platelet pellet resuspended in Hepes buffer ( $5 \mathrm{mmol} / \mathrm{l}$ Hepes, $137 \mathrm{mmol} / 1$ sodium chloride, $2.7 \mathrm{mmol} / \mathrm{l}$ potassium chloride, $1.2 \mathrm{mmol} / 1$ magnesium chloride, $12 \mathrm{mmol} / \mathrm{l}$ sodium bicarbonate, $0.4 \mathrm{mmol} / 1$ sodium biphosphate, and 0.6 $\mathrm{mmol} / \mathrm{l}$ glucose, $\mathrm{pH} 7.4$ ) at a platelet concentration of $10^{12} / 1$.

\section{Lipoproteins}

Blood was drawn into $1 \mathrm{~g} / 1$ disodium EDTA. LDL was separated by discontinuous density gradient ultracentrifugation (9) and dialysed extensively against Hepes buffer in the presence of $0.3 \mathrm{mmol} / 1$ EDTA. The purity of LDL was analysed by cellulose acetate electrophoresis and by Ouchterlony double immunodiffusion and immunoelectrophoresis. Lipoprotein protein concentration was determined using the Bio-Rad protein assay (10) (Bio-Rad Laboratories, Richmond, CA), and total and free cholesterol concentrations by the method of Chlamori \& Henry (11). LDL was acetylated by repeated addition of acetic anhydride/sodium acetate (12). LDL iodination was performed by a modification of the iodine monochloride method (13).

\section{Incubation procedure}

LDL (650 mg of protein per litre) was incubated with or without washed platelets in Hepes buffer. A $4 \mathrm{ml}$ platelet suspension was used in a concentration of $10^{12} / 1$ and incubated for $2 \mathrm{~h}$ at $37^{\circ} \mathrm{C}$. At the end of the incubation period the platelets were removed by centrifugation at $1500 \mathrm{~g}$ for $10 \mathrm{~min}$, and LDL was reseparated from the supernatant by ultracentrifugation at a density of $1.210 \mathrm{~kg} / \mathrm{l}$. The appropriate control (LDL incubated without platelets) was also included. The lipoproteins were dialysed extensively against Hepes buffer containing $0.3 \mathrm{mmol} / \mathrm{l}$ EDTA and analysed for protein and total, free and esterified cholesterol concentrations. The platelet pellet contained LDL as determined by double immunodiffusion against anti-LDL. Upon incubation of ${ }^{125} \mathrm{I}$-labelled LDL $(10 \mathrm{mg} / \mathrm{l})$ with washed platelets, $10-16 \%$ of the radioactivity was found to be plateletassociated.

Platelet-conditioned medium was prepared from washed platelets (their number equal to that used in platelet-modified LDL formation) and incubated for $2 \mathrm{~h}$ at $37^{\circ} \mathrm{C}$, followed by platelet removal by centrifugation at $1500 \mathrm{~g}$ for $10 \mathrm{~min}$. LDL ( $450 \mathrm{mg}$ of protein per litre) was then added to the platelet-conditioned medium and incubated for $2 \mathrm{~h}$ at $37^{\circ} \mathrm{C}$. Similarly, ${ }^{125}$ I-labelled $\mathrm{LDL}$ was prepared in the presence of $10 \mathrm{mg} / \mathrm{l}^{125} \mathrm{I}$-labelled LDL.

In some experiments, platelet-conditioned medium was prepared from washed platelets activated by the addition of $5 \cdot 10^{3}$ units per litre thrombin for the entire incubation period. The platelet-conditioned medium was treated with $5 \cdot 10^{3}$ units per litre hirudin to remove the thrombin.

After incubation of platelet-conditioned medium with LDL, the LDL was reisolated as described for the platelet-modified LDL system. Platelet-conditioned medium alone, incubated without LDL, was also studied for its effect on macrophage cholesterol metabolism.

\section{Platelet aggregation}

The lipoproteins (control and platelet-modified LDL) were initially incubated with normal washed platelets $\left(0.3 \times 10^{12} / 1\right)$ for $30 \mathrm{~min}$ at $37^{\circ} \mathrm{C}$. Platelet aggregation, measured as a percentage of maximal amplitude, was studied with collagen $(1 \mathrm{mg} / \mathrm{l})$ as aggregating agent (14), using the appropriate controls without platelets, in a PAP-4 computerized aggregometer (Bio-Data Corporation, Hatboro, PA).

\section{Mouse peritoneal macrophages}

Cells were harvested from the peritoneal fluid of 10 female $\mathrm{BALB} / \mathrm{c}$ mice $(15-25 \mathrm{~g}) 4$ days after intraperitoneal injection into each mouse of $3 \mathrm{ml} 24 \mathrm{~g} / \mathrm{l}$ thioglycolate in saline (15). The cells $\left(10-20 \times 10^{6} /\right.$ mouse) were pooled, treated with $3 \mathrm{ml} 8.3$ $\mathrm{g} / \mathrm{l}$ chloride, $\mathrm{pH} \mathrm{7.4}$, and incubated for $5 \mathrm{~min}$ at $37^{\circ} \mathrm{C}$ to remove red blood cell contamination. The cells were washed and centrifuged three times with phosphate-buffered saline at $400 \mathrm{~g}$ for 10 min, then resuspended to $10^{9} / 1$ in Dulbecco's modified Eagle's medium containing horse serum (heat inactivated at $56^{\circ} \mathrm{C}$ for $30 \mathrm{~min}$, volume fraction 0.15 ), $100 \mathrm{kU} / \mathrm{l}$ penicillin and $100 \mathrm{mg} / \mathrm{l}$ streptomycin. The cell suspension was dispensed into 60 or 100 mm plastic Petri dishes and incubated in a humidified $5 \% \mathrm{CO}_{2}$ incubator for $2 \mathrm{~h}$. The dishes were washed once with $5 \mathrm{ml}$ Dulbecco's modified Eagle's medium to remove nonadherent cells, and the monolayer was then incubated under similar conditions for $18 \mathrm{~h}$. The medium was then changed to Dulbecco's modified Eagle's medium containing $2 \mathrm{~g} / \mathrm{l}$ bovine serum albumin, either without any additions (control) or with the addition of the lipoproteins at various concentrations for $18 \mathrm{~h}$.

At the end of the incubation period the cells were washed three times with phosphate buffered saline, then collected in $2-4 \mathrm{ml}$ phosphate buffered saline using a rubber policeman and sedimented at $400 \mathrm{~g}$ for $10 \mathrm{~min}$. The cell pellet was resuspended in $1.2 \mathrm{ml}$ distilled water and sonicated twice for $20 \mathrm{~s}$ at $80 \mathrm{~W}$. An aliquot of $0.1 \mathrm{ml}$ was taken for protein determination, and lipids were extracted from the remainder with chloroform/ methanol $(2+1$, by vol.). Total and free macrophage cholesterol (precipitated with digitonin), were then determined (11). The cholesterol esterification rate in macrophages was measured as the incorporation of $\left.{ }^{3} \mathrm{H}\right]$ oleic acid into cellular cholesteryl $\left[{ }^{3} \mathrm{H}\right]$ oleate as described by Goldstein et al. (16). Macrophages were incubated in medium containing $\left[{ }^{3} \mathrm{H}\right]$ oleate complexed with albumin $(83 \mathrm{nmol}$ oleate per $\mathrm{mg}$ albumin, 370 $\mathrm{MBq} / \mathrm{l}$; Amersham Radiochemical Centre, Amersham, Bucks., $\mathrm{UK}$ ) at a final oleate concentration of $0.27 \mathrm{mmol} / \mathrm{l}$, in the presence or absence of lipoproteins. At the end of the incubation period and after cell lipid extraction, lipids were separated by thin-layer chromatography and developed in - hexane/ether/ acetic acid $(80+20+1.5$, by vol.). The cholesteryl ester spots were visualized with iodine vapour, scraped into vials containing $15 \mathrm{ml}$ scintillation fluid, and counted in a beta-scintillation counter. 
Macrophage cholesterol synthesis was determined using 370 $\mathrm{MBq} / 1\left[{ }^{3} \mathrm{H}\right]$ acetate, $1.25 \mathrm{mmol} / \mathrm{l}$ (Amersham), in the cell incubation system. After $18 \mathrm{~h}$ of incubation, lipids were extracted and separated as described above. Macrophage cholesterol synthesis was measured as incorporation of $\left[{ }^{3} \mathrm{H}\right]$ acetate into $\left[{ }^{3} \mathrm{H}\right]$ cholesterol. Degradation of ${ }^{125} \mathrm{I}$-labelled LDL by macrophages was studied as described elsewhere (12).

\section{Statistics}

For each experiment, duplicate or triplicate parallel cultures were incubated. The Wilcoxon rank test was used to evaluate the significance of the results.

\section{Results}

Two hours after the incubation of washed platelets in Hepes buffer at $37^{\circ} \mathrm{C}$, a substantial loss (up to $20 \%$ ), of platelet lipids and protein had occurred without changes in platelet aggregation (fig. 1). The addition of bovine serum albumin or apyrase (which removed released ADP) did not significantly affect the loss of lipids and protein. Figure 2 demonstrates that various aggregating agents also had only little effect on the loss of platelet cholesterol and protein, except for arachidonic acid, which caused $43 \%$ greater release of total platelet cholesterol than in the control samples.

The lipid and protein losses were related to platelet concentration and were not affected by the presence of LDL in the medium (fig. 3). From these studies (figs. $1-3$ ) we chose the appropriate incubation conditions for producing platelet-modified LDL.

When washed platelets $\left(10^{12} / 1\right)$ were incubated with $650 \mathrm{mg} / 1 \mathrm{LDL}$ for $2 \mathrm{~h}$ at $37^{\circ} \mathrm{C}$, followed by $\mathrm{LDL}$ separation by recentrifugation, the platelet-modified LDL demonstrated a significant reduction of 15$25 \%$ in LDL protein and cholesterol (free and esterified) content (fig. 4). These changes resulted in a decreased ratio of free cholesterol to protein in the modified LDL, compared with the control LDL (incubated without platelets). Table 1 demonstrates that the change in LDL composition caused by plateletconditioned medium derived from normal washed platelets was similar to that caused by platelet suspension (fig. 4). The absence of lactic dehydrogenase activity in the incubation medium suggests that the platelets did not release their cytoplasmic contents. Similarly, when platelet-conditioned medium was derived from thrombin-activated platelets $\left(10 \cdot 10^{3} \mathrm{U} / \mathrm{l}\right.$, $2 \mathrm{~h}$ at $37^{\circ} \mathrm{C}$, and then thrombin removal by $10 \cdot 10^{3}$ $\mathrm{U} / 1$ hirudin), it caused a decrease in LDL cholesterol and protein from $1.56 \pm 0.34$ and $1.10 \pm 0.26 \mathrm{mmol} / \mathrm{l}$ to $1.00 \pm 0.27$ and $1.01 \pm 0.26 \mathrm{mmol} / \mathrm{l}$, respectively.
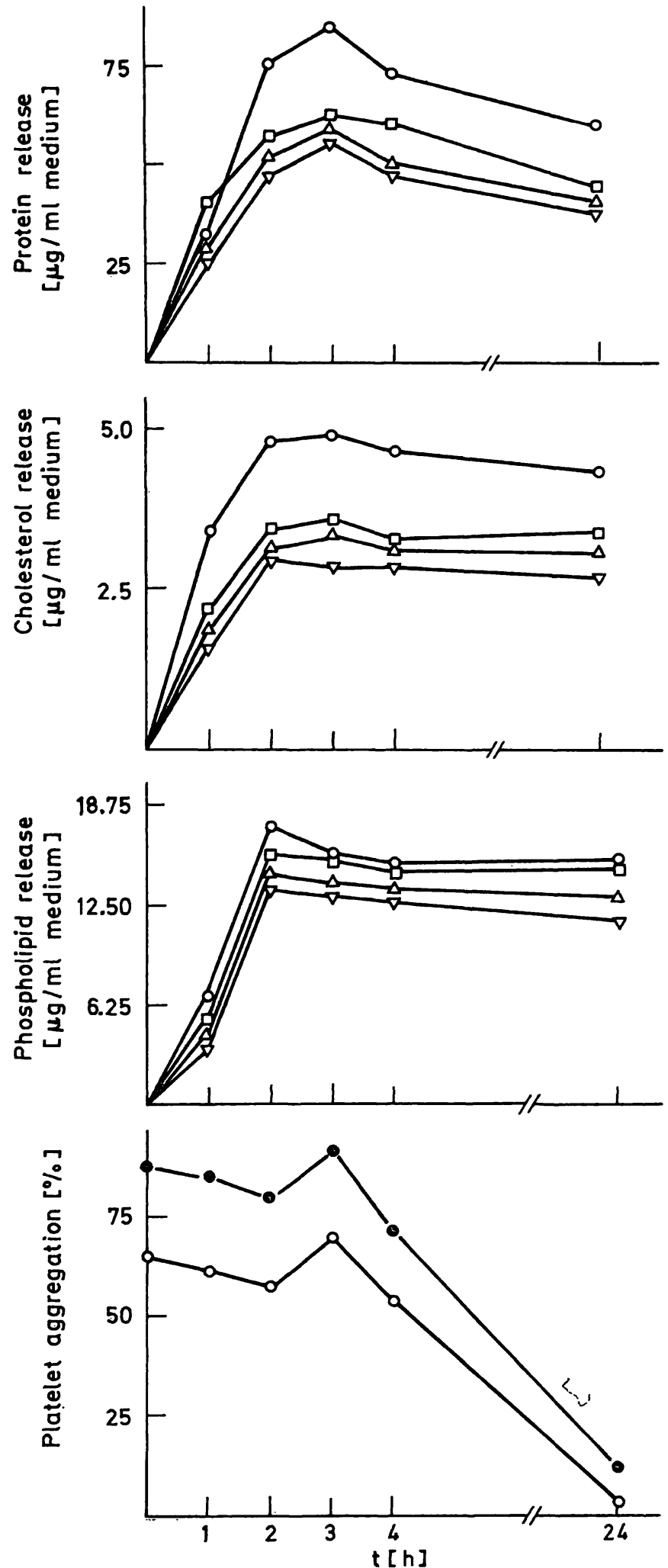

Fig. 1. Influence of incubation time and medium composition on platelet release of total cholesterol, phospholipids, and protein, and on platelet aggregation. Washed platelets $\left(10^{12} / 1\right)$ were incubated in Hepes buffer for the indicated time at $37^{\circ} \mathrm{C}$, with no addition (o), with the addition of $3.5 \mathrm{~g} / \mathrm{l}$ albumin $(\square), 100 \mathrm{mg} / \mathrm{l}$ apyrase $(\Delta)$ or both $(\nabla)$. At the end of the incubation period, the platelets were removed by centrifugation at $1000 \mathrm{~g}$ for $15 \mathrm{~min}$, and the supernatant was used for analysis $(\mathrm{mg} / \mathrm{l})$ of protein, cholesterol, and phospholipids. Platelet aggregation induced by $5 \mu \mathrm{mol} / 1 \mathrm{ADP}(0)$ or $1 \mathrm{mg} / \mathrm{l} \mathrm{col-}$ lagen (๑) was studied with a separate platelet suspension. Each point represents the mean of three separate results which differed by less then $4 \%$. 

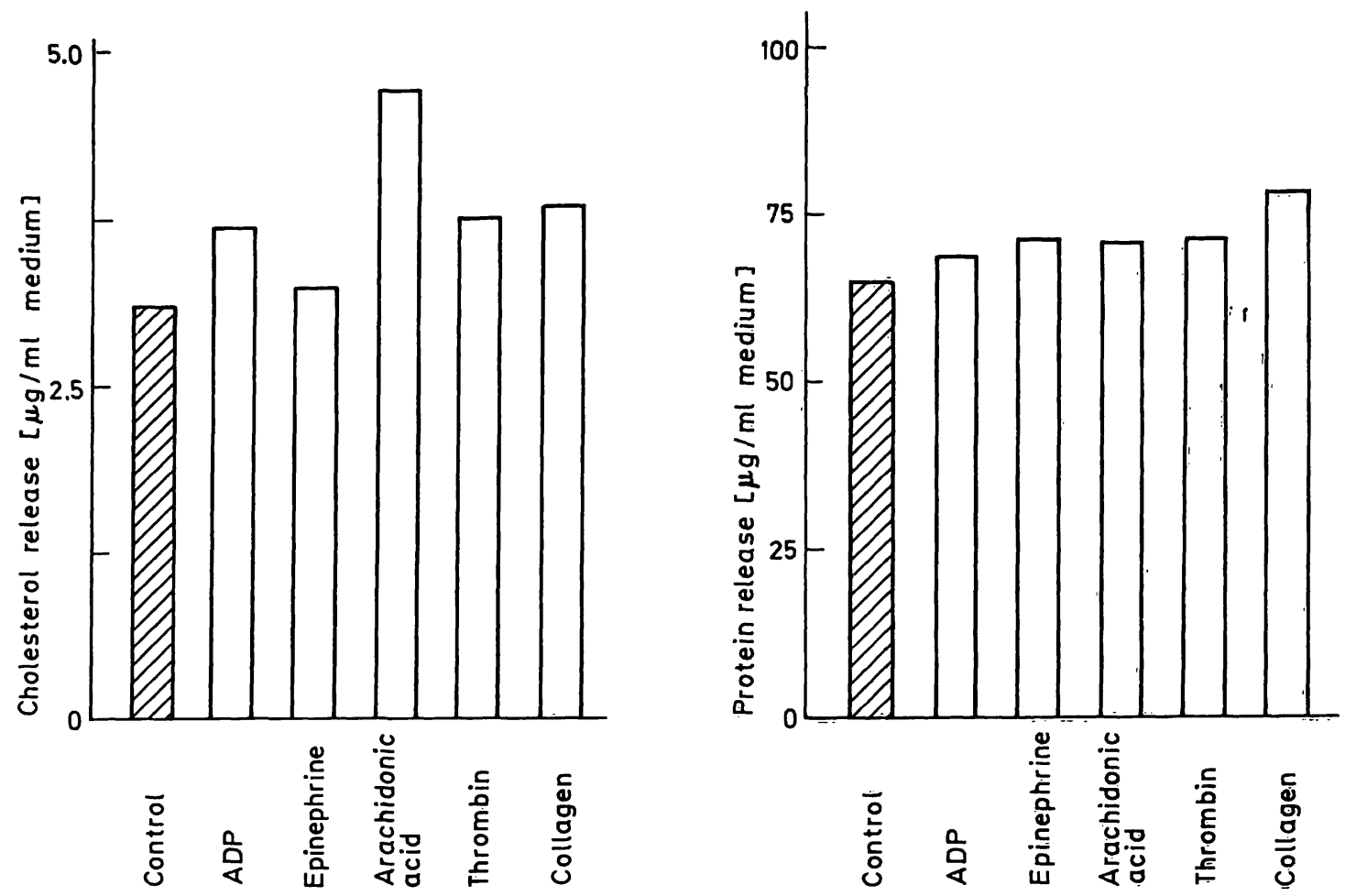

Fig. 2. Effect of various aggregating agents on release of platelet cholesterol and protein. Washed platelet $\left(10^{12} / 1\right)$ were incubated in Hepes buffer for $2 \mathrm{~b}$ at $37^{\circ} \mathrm{C}$, either alone (control) or with the addition of one of the following aggregating agents: $50 \mu \mathrm{mol} / \mathrm{l} \mathrm{ADP}, 0.1 \mathrm{~g} / \mathrm{l}$ epinephrine, $5 \mathrm{mmol} / \mathrm{l}$ arachidonic acid, $10 \cdot 10^{3} \mathrm{U} / \mathrm{l}$ thrombin, and $10 \mathrm{mg} / \mathrm{l}$ collagen. At the end of the incubation period and after platelet removal by centrifugation, supernatant cholesterol and protein concentrations $(\mathrm{mg} / \mathrm{l})$ were determined. Results represent mean of three separate experiments which differ by less thañ $3 \%$.

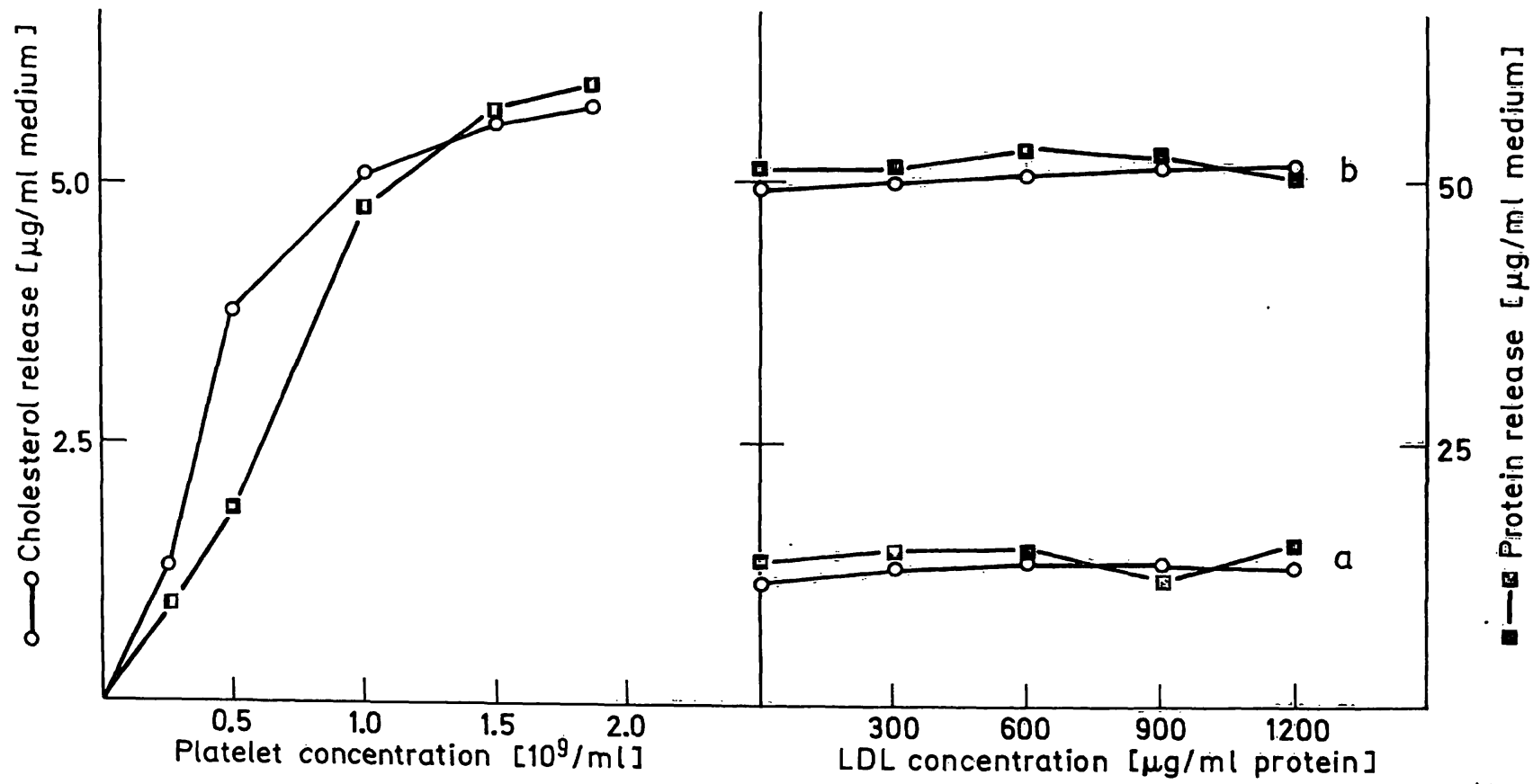

Fig. 3. Effect of platelet and LDL concentration on platelet cholesterol (O) and protein ( $\square$ ) release. Washed platelets were incubated in Hepes buffer for $2 \mathrm{~h}$ at $37^{\circ} \mathrm{C}$ using either increasing platelet concentrations without LDL (left) or increasing LDL concentrations with fixed platelet concentration of either (a) 0.5 or (b) $1.25 \times 10^{12} / 1$ (right).

When washed platelets $\left(300 \cdot 10^{9} / \mathrm{l}\right)$ were incubated with increasing concentrations of platelet-modified LDL for $30 \mathrm{~min}$ at $37^{\circ} \mathrm{C}$, collagen $(1 \mathrm{mg} / \mathrm{l})$-induced platelet aggregation significantly increased (by $12 \%$ ), compared with the effect of control LDL (fig. 5).
Similarly, LDL modified by platelet-conditioned medium also significantly increased normal washed platelet aggregation (tab. 2). Platelet-conditioned medium derived from thrombin activated platelets also modified LDL in a similar way. At a cholesterol 


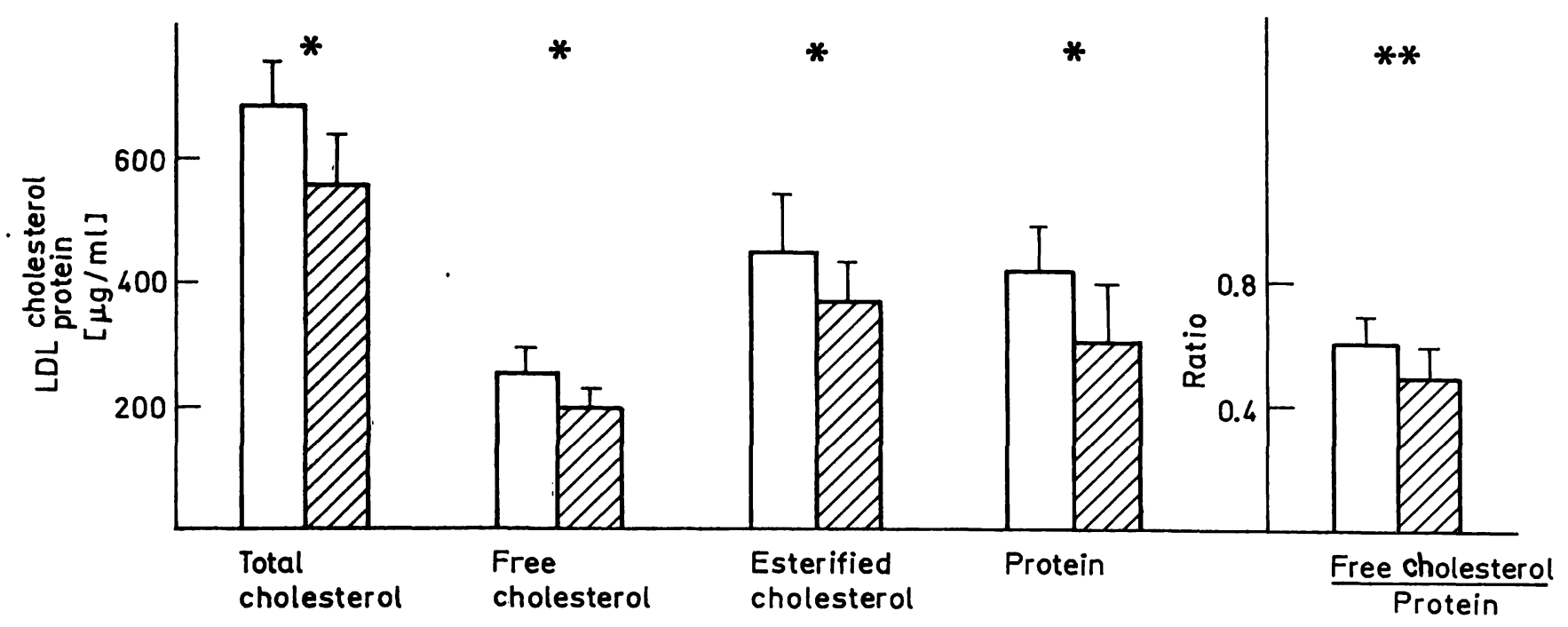

Fig. 4. Cholesterol and protein content of platelet-modified LDL ( $\square$ ) compared with control LDL ( $\square$ ). For details, see Methods. Results are mean \pm SD of 15 experiments. ${ }^{* P}<0.01 ; * \mathrm{P}<0.02$ (platelet-modified LDL versus control LDL). To convert $\mu \mathrm{g} / \mathrm{ml}$ to $\mathrm{mmol} / \mathrm{l}$ multiply the cholesterol value by 2.60 , and the phospholipid value by 1.28 .

Tab. 1. Cholesterol and protein concentrations of control LDL and platelet-conditioned medium-treated LDL

\begin{tabular}{|c|c|c|c|c|c|}
\hline & \multicolumn{3}{|l|}{ Cholesterol } & \multirow[t]{2}{*}{ Protein } & \multirow{2}{*}{$\frac{\text { Free cholesterol }}{\text { Protein }}$} \\
\hline & total & free & esterified & & \\
\hline $\begin{array}{l}\text { Control LDL } \\
\text { Modified LDL }\end{array}$ & $\begin{array}{l}1.77 \pm 0.28 \\
1.46 \pm 0.26^{*}\end{array}$ & $\begin{array}{l}0.65 \pm 0.12 \\
0.54 \pm 0.10^{*}\end{array}$ & $\begin{array}{l}1.12 \pm 0.24 \\
0.92 \pm 0.21\end{array}$ & $\begin{array}{l}419 \pm 88 \\
389 \pm 79 *\end{array}$ & $\begin{array}{l}0.59 \pm 0.12 \\
0.52 \pm 0.11^{*}\end{array}$ \\
\hline
\end{tabular}

Results are mean \pm SD of 12 experiments, expressed as mmol/l for the lipids, mg/l for protein and weight ratio for free cholesterol/protein.

$* \mathrm{P}<0.05$ (modified LDL versus control LDL).

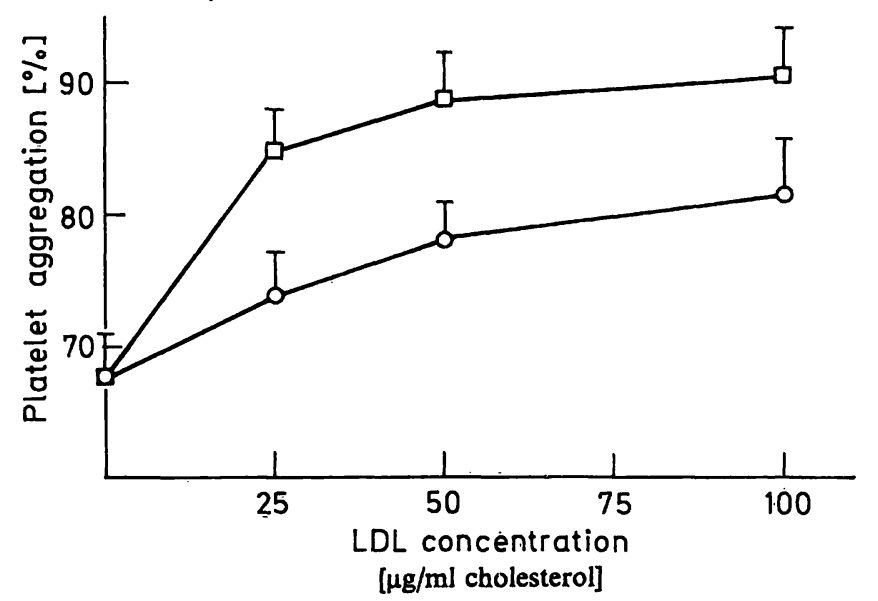

Fig. 5. Platelet aggregation induced by platelet-modified LDL $(\square-\square)$ and by control LDL $(0-0)$. The lipoproteins were incubated with normal washed-platelet suspension $\left(300 \times 10^{9} / 1\right)$ for $30 \mathrm{~min}$ at $37^{\circ} \mathrm{C}$, using three different LDL concentrations, prior to analysis of platelet aggregation induced by $1 \mathrm{mg} / 1$ collagen. Results are mean $\pm \mathrm{SD}$ of seven experiments $(\mathrm{P}<0.01$ for platelet-modified LDL vs. LDL). concentration of $50 \mathrm{mg} / \mathrm{l}, \mathrm{LDL}$ modified by plateletconditioned medium caused $93 \pm 8 \%$ aggregation, compared with $81 \pm 6 \%$ for control LDL.

When mouse peritoneal macrophages were incubated with platelet-modified LDL for $18 \mathrm{~h}$ at $37^{\circ} \mathrm{C}$, the macrophage total cholesterol content was significantly elevated, compared with the effect of control LDL (fig. 6). This cellular cholesterol elevation was due mainly to elevation of the cholesterol ester fraction. LDL modified by platelet-conditioned medium caused a similar elevation in macrophage cholesterol ester, but this was only $73 \%$ of the level achieved with platelet-modified LDL (fig. 6). The cholesterol esterification rate, measured as the amount of $\left[{ }^{3} \mathrm{H}\right]$ oleic acid incorporated into cellular cholesterol ester, also significantly increased in macrophages following incubation with increasing concentrations of platelet-

Tab. 2. Effect of platelet-conditioned medium-treated LDL on platelet aggregation (\%)

\begin{tabular}{lllll}
\hline & \multicolumn{4}{l}{ Lipoprotein concentration (mmol cholesterol per litre) } \\
\cline { 2 - 5 } & 0 & 25 & 50 & 100 \\
\hline Control LDL & $0.18 \pm 0.018$ & $0.19 \pm 0.016$ & $0.21 \pm 0.018$ & $0.22 \pm 0.018$ \\
Modified LDL & $0.18 \pm 0.018$ & $0.22 \pm 0.013^{*}$ & $0.24 \pm 0.018^{*}$ & $0.26 \pm 0.016^{*}$ \\
\hline
\end{tabular}

* $\mathrm{P}<0.01$ (modified LDL versus control LDL) $(n=5)$. 


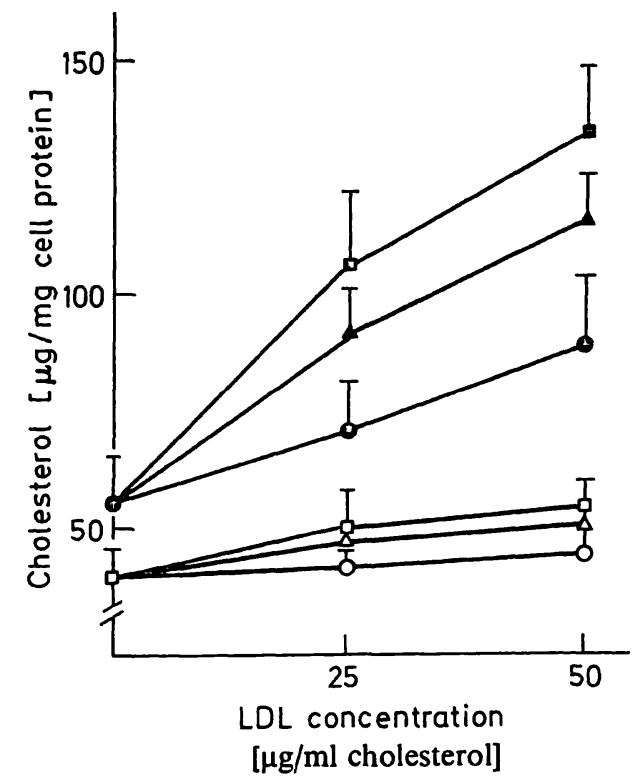

Fig. 6. Effect of platelet-modified LDL $(\square$ व) and plateletconditioned medium treated $\operatorname{LDL}(\Delta, \Delta)$ and control $\operatorname{LDL}(\bullet, 0)$ on macrophage cholesterol content. Mouse peritoneal macrophages $\left(10^{7} /\right.$ dish) were incubated for $18 \mathrm{~h}$ at $37^{\circ} \mathrm{C}$ in Dulbecco's modified Eagle's medium containing $2 \mathrm{~g} / \mathrm{l}$ bovine serum albumin and either LDL, platelet-modified LDL, or platelet-conditioned medium-treated LDL, using increasing lipoprotein concentrations. Macrophage total cholesterol (closed symbols) and free cholesterol (open symbols) content were then determined. Results represent mean \pm SD of seven experiments (for total cholesterol $P<0.01$ for plateletmodified LDL vs. control LDL). modified LDL (fig. 7a); this was up to $70 \%$ more than the effect of control LDL. LDL and both modified LDLs, when incubated with macrophages for $18 \mathrm{~h}$, caused a reduction in mouse peritoneal macrophage cholesterol synthesis, measured as $\left[{ }^{3} \mathrm{H}\right]$ acetate incorporated into cellular cholesterol (fig. 7b). The decreases caused by both modified LDL however, were $50 \%$ and $28 \%$ greater than that caused by control LDL.

Similar results, although of lesser magnitude, were obtained when LDL modified by platelet conditioned medium was used instead of platelet-modified LDL (fig. $7 \mathrm{a}$ and $7 \mathrm{~b}$ ). Table 3 demonstrates that plateletconditioned medium derived from thrombin-activated platelets caused the formation of a modified LDL, which had an effect on mouse peritoneal macrophage cholesterol metabolism similar to that of LDL modified by platelet-conditioned medium prepared from nonactivated p!atelets (fig. 7). When acetyl-LDL (50 $\mathrm{mg} / \mathrm{l})$ was incubated with macrophages for $18 \mathrm{~h}$ at $37^{\circ} \mathrm{C}$, we found a dramatic increase of $350 \%$ in the cellular cholesterol ester content and esterification, and a $60 \%$ decrease in cellular cholesterol synthesis, compared with controls containing LD̈L.

The elevation in macrophage cholesterol esterification rate by LDL and platelet-modified LDL was time dependent and maximal within $24 \mathrm{~h}$ of incubation
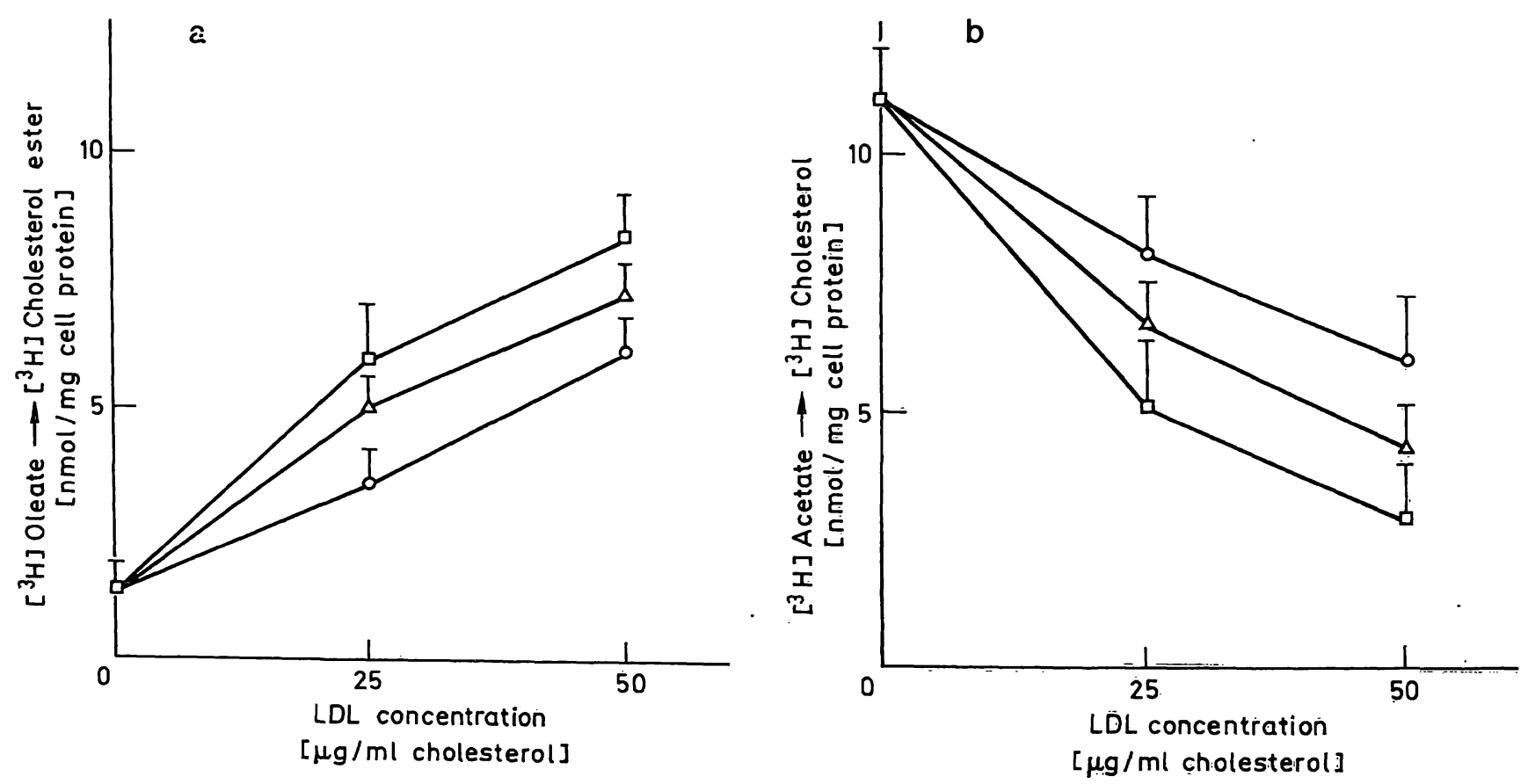

Fig. 7. Influence of platelet-modified LDL and platelet-conditioned medium-treated LDL on macrophage cholesterol esterification rate and on cholesterol synthesis. Mouse peritoneal macrophages were incubated with LDL $(0)$, platelet-modified LDL (a) or platelet-conditioned medium-treated LDL $(\Delta)$ for $18 \mathrm{~h}$ at $37^{\circ} \mathrm{C}$ in the presence of $\left.370 \mathrm{MBq} / 1{ }^{3} \mathrm{H}\right]$ oleic acid (a) or of $\left[{ }^{3} \mathrm{H}\right]$ acetate (b). After analysis of the cellular lipid extract by thin-layer chromatography, the radioactivity in the free cholesterol spot was determined. Results represent mean $\pm S D$ of six experiments $(P<0.01$ for platelet-modified LDL
vs. control LDL). 
Tab. 3. Effect of platelet-modified LDL produced by activated platelets on mouse peritoneal macrophage cholesterol metabolism

\begin{tabular}{llll}
\hline & $\begin{array}{l}\text { Total cholesterol } \\
\text { (nmol/mg cell protein) }\end{array}$ & $\begin{array}{l}\text { Cholesterol esterification } \\
\text { (nmol/mg cell protein) }\end{array}$ & $\begin{array}{l}\text { Cholesterol synthesis } \\
\text { (nmol/mg cell protein) }\end{array}$ \\
\hline Control LDL & 180 & 6.1 & 7.3 \\
Modified LDL & 221 & 9.7 & 4.5 \\
\hline
\end{tabular}

For details see Incubation Procedure under Methods.

Results represent the mean of three experiments with a similar pattern and a maximal variation of $8 \%$.

(fig. 8). The macrophage cholesterol esterification rate was not significantly affected by cellular cholesterol biosynthesis inhibition with $0.4 \mathrm{mg} / 1$ mevinolin (fig. 8). Degradation of ${ }^{125} \mathrm{I}$-labelled LDL modified by platelet-conditioned medium showed saturable kinetics in mouse peritoneal macrophages (fig. 9A), and its degradation was competitively inhibited by native LDL but not by acetyl LDL (fig. 9B). Both modified LDLs and control LDL displayed similar mobilities in immunoelectrophoretic analysis. On $2.5 \%$ SDSPAGE analysis no apolipoprotein B fragments were found (although small molecular weight fragments

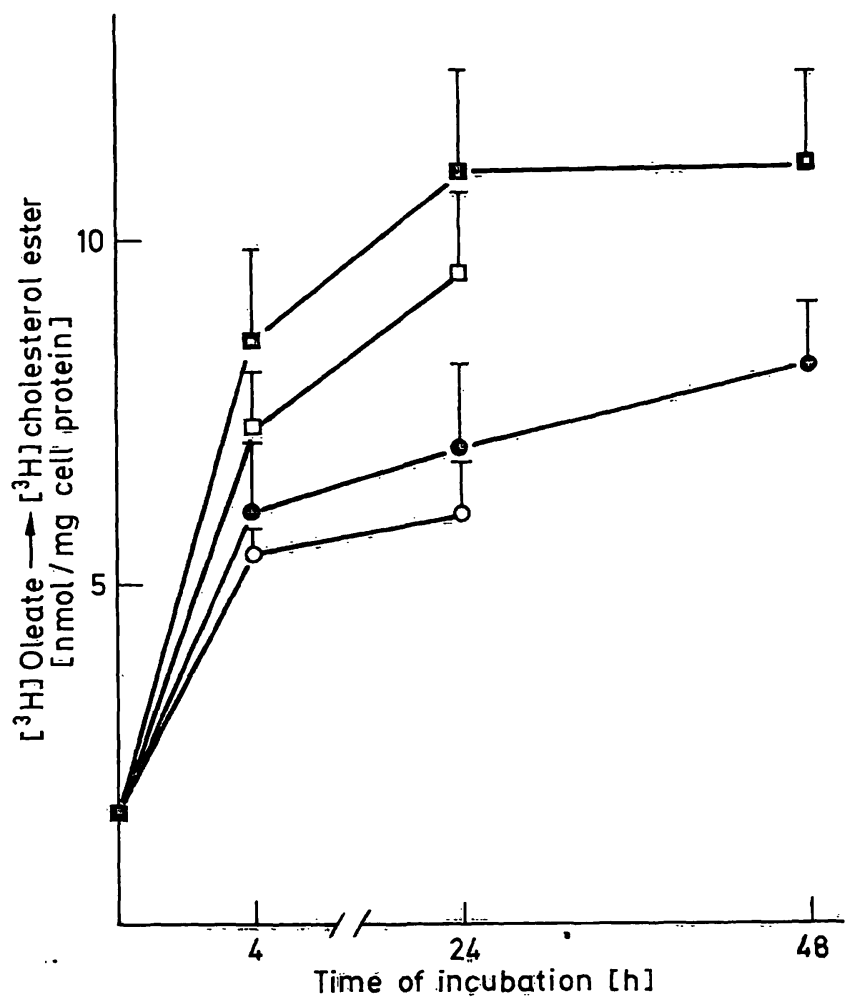

Fig. 8. Effect of time of incubation of macrophage with platelet-modified LDL $(\square, \square)$ and $\operatorname{LDL}(0, \bullet)$ on cellular cholesterol esterification, and the influence of mevinolin. Mevinolin inhibited cholesterol synthesis by more than $90 \%$, as determined by the incorporation of $\left[{ }^{3} \mathrm{H}\right]$ acetate into free cholesterol. Incubation was carried out without (closed symbols) or with (open symbols) mevinolin $(400 \mathrm{mg} / \mathrm{l})$. Results represent mean $\pm \mathrm{SD}$ of 4 experiments. may not be detected by these gels). Platelet-conditioned medium contained two major protein bands corresponding to relative molecular masses of 60000 and 100000 . Platelet-modified LDL also inhibits the degradation of ${ }^{125}$ I-labelled LDL modified by plateletconditioned medium by macrophages (data not shown).

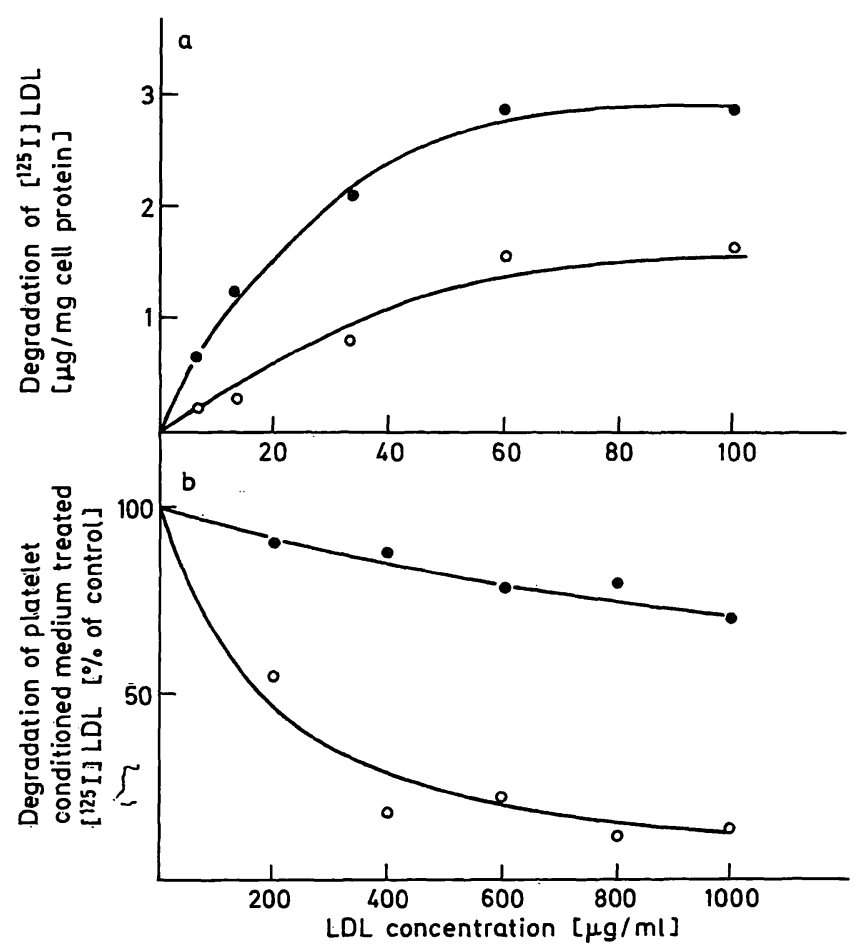

Fig. 9. Degradation of platelet-conditioned medium-treated LDL by mouse peritoneal macrophages. ${ }^{125} \mathrm{I}$-labelled LDL was incubated without or with platelet-conditioned medium as described under Methods.

a) Macrophages were incubated with increasing concentrations of either ${ }^{125}$ I-labelled LDL $(0-0)$ or plateletconditioned medium-treated ${ }^{125}$ I-labelled LDL $(0-0$, 165 counts $/ \mathrm{min} \cdot \mu \mathrm{g}$ ) for $5 \mathrm{~h}$ at $37^{\circ} \mathrm{C}$ prior to analysis of LDL degradation.

b) $10 \mathrm{mg} / \mathrm{l}$ of platelet-conditioned medium-treated ${ }^{125} \mathrm{I}$ labelled LDL were incubated with macrophages in the presence of increasing concentrations of either LDL $(0-0)$ or acetylated LDL $(0-0)$ for $5 \mathrm{~h}$ at $37^{\circ} \mathrm{C}$ followed by analysis of the radiolabelled LDL degradation.

Results represent the mean of 3 separate experiments. 
Following incubation of platelet-conditioned medium (25 mg protein per litre) with normal washed platelets $\left(0.3 \cdot 10^{12} / \mathrm{l}\right)$, collagen $(1 \mathrm{mg} / \mathrm{l})$-induced platelet aggregation was reduced from $76 \pm 12 \%$ to $65 \pm 8 \%$; a similar effect was obtained with $50 \mu \mathrm{g}$ platelet-conditioned medium protein per litre $(p<0.01)$.

Platelet-conditioned medium alone (not interacting with LDL), when incubated with macrophages, increased the cellular cholesterol content and esterification, and reduced cellular cholesterol synthesis (tab. 4), in comparison with the control which contained no additions; these effects, however, were less than those caused by the lipoproteins (figs. 6, 7). The addition of platelet-conditioned medium, together with control LDL or LDL modified by platelet-conditioned medium to the macrophages, results in an additive effect (tab. 5), implying separate mechanisms for cell cholesterol uptake induced by platelet-conditioned medium and by the lipoproteins. The lipids and proteins released from the platelet did not float up at a density of $1.210 \mathrm{~kg} / \mathrm{l}$, but remained in the infranatant.

\section{Discussion}

This study demonstrates that material released from platelets, can influence two different biochemical events. It can directly increase the macrophage cholesterol content and reduce in vitro platelet aggrega- tion, and it can also modify LDL in such a way that the modified lipoprotein increases platelet aggregation and causes cholesterol accumulation in mouse peritoneal macrophages.

Although it could be suggested that the effect of LDL modified by platelet-conditioned medium on macrophage cholesterol metabolism is the ressult of the action of a factor in platelet-conditioned medium (which may float together with the reisolated LDL), rather than associated with the lipoprotein, our data suggest two separate mechanisms for platelet-conditioned medium and LDL modified by platelet-conditioned medium.

We were able to show that the lipids and protein released from platelets did not float at a density of $1.210 \mathrm{~kg} / 1$ and thus the platelet-conditioned medium lipids and protein could not be directly linked to the effect of the lipoproteins. Furthermore, when plateletconditioned medium was incubated with macrophages in the presence of control LDL or in the presence of LDL modified by platelet-conditioned medium the cholesterol content of the cells was in fact a result of an additive effect, implying that platelet-conditioned medium contributed to the macrophage cholesterol content independently of the contribution of LDL modified by platelet-conditioned medium. Plateletconditioned medium also displayed opposing effects to that of LDL modified by platelet-conditioned medium on in vitro platelet aggregation, suggesting again that LDL modified by platelet-conditioned medium

Tab. 4. The effect of platelet-conditioned medium on macrophage cholesterol metabolism.

\begin{tabular}{lllr}
\hline $\begin{array}{l}\text { Platelet-conditioned medium } \\
\text { (mg protein per litre) }\end{array}$ & Total cholesterol & Cholesterol esterification & Cholesterol synthesis \\
& (nmol/mg cell protein) & (nmol/mg cell protein) & (nmol/mg cell protein) \\
\hline 0 & $148 \pm 18$ & $1.3 \pm 0.4$ & $11.1 \pm 2.3$ \\
25 & $159 \pm 18$ & $1.5 \pm 0.3$ & $10.2 \pm 1.7$ \\
50 & $180 \pm 20$ & $1.9 \pm 0.4^{*}$ & $9.3 \pm 1.6^{*}$ \\
\hline
\end{tabular}

Results are the mean \pm SD of five experiments.

${ }^{*} \mathrm{P}<0.02$ (platelet-conditioned medium versus control)

Tab. 5. Effect of platelet-conditioned medium in the presence of LDL on macrophage cholesterol content

+ platelet-conditioned medium + control LDL

+ platelet-conditioned medium-treated LDL ( $25 \mathrm{mg}$ protein per litre)

+ platelet-conditioned medium + platelet-conditioned medium-treated LDL 
and platelet-conditioned medium act separately through different mechanisms.

Macrophages possess significant quantities of LDL receptors capable of binding LDL (17). Macrophage cholesterol accumulation following incubation with control LDL could be the result of the expression of LDL binding sites in response to the stimulation of the mice with thioglycolate. It could be the result of an unusual apolipoprotein B, E (LDL) receptor (17) and also of a non-receptor interaction between LDL and macrophages. LDL modified by platelet-conditioned medium substantially increased the macrophage cholesterol content and esterification rate, and decreased cellular cholesterol synthesis, compared with control LDL. A similar pattern has been described for chemically and biologically modified LDL $(18-20)$. On the other hand endothelial-cell-modified LDL was formed only in the presence of the cells but not in the presence of the cell-conditioned medium (20). However, unlike the other modified LDL preparations, LDL modified by platelet-conditioned medium reacts with the LDL receptor and not with the scavenger binding sites as suggested from the competition experiments of ${ }^{125}$ I-labelled LDL modified by platelet-conditioned medium with native LDL and acetyl LDL. The greater ability of LDL modified by platelet-conditioned medium to cause macrophage cholesterol accumulation, compared with the effect of control LDL (even though they both bind to the same receptors) could be attributed to increased receptor uptake. This, in turn, may be due to the affinity of LDL modified by platelet-conditioned medium for the LDL receptors, compared with control LDL. Furthermore, the intracellular metabolism of cholesterol may differ, depending on whether it is derived from LDL or from LDL modified by platelet-conditioned medium.

Activated platelets have been shown to release lipidprotein particles with platelet factor 3 like activity (21), and it was also demonstrated recently that membrane microvesicles could be formed from platelets (22). The lipids and protein which are lost from the platelets are very probably originated from the platelet granules and are released to the medium during incubation. The incubation itself could activate the platelets and this might be the reason that activation of platelets with various aggregating agents did not cause further modifications of the lipoprotein. We have demonstrated that lipids and protein released from platelets can affect lipoprotein composition (23). It was also shown $(7,24)$ that platelet activation results in the release of lipids which in turn affect cholesterol accumulation in smooth muscle cells and in macrophages. Similarly, platelet-conditioned medium in our study was found to increase the macrophage cholesterol content.

No significant changes were found in the thiobarbituric acid reactive material expressed as malondialdehyde concentrations, suggesting that LDL oxidation was not induced in LDL modified by platelet-conditioned medium formation and that LDL modified by platelet-conditioned medium is not malondialdehydeLDL (19). Some of the platelet material associated with LDL may include some aggregation-promoting substances released from the platelet granules, and this could account for the increased in vitro platelet aggregation. Platelets possess specific binding sites for LDL (6), and the decrease of LDL constituents in LDL modified by platelet-conditioned medium could be related in part to LDL binding to a substance or substances released from the platelets. Thus, plateletLDL interaction could result in removal of some subset of LDL, leaving a "hyperactive" subset behind.

The materials released from the platelets and responsible for the modification of the LDL molecule are possibly platelet lipase, protease or lipid transferase. Alternatively, this platelet-released material might activate LDL-associated protease, phospholipase or other LDL-bound enzymes (25).

The effect of platelet-modified LDL on macrophage cholesterol metabolism was similar to that already shown for other LDL preparations (26); LDL uptake by the cells results in lysosomal cholesterol ester hydrolysis, followed by reesterification and a parallel reduction in cell cholesterol synthesis. The inhibition of cholesterol synthesis with mevinolin did not affect cell cholesterol esterification, suggesting that the cholesterol ester of LDL modified by platelet-conditioned medium itself (and not the cholesterol derived from biosynthesis) contributed to macrophage cholesterol accumulation.

Macrophage cholesterol accumulation and platelet activation represent parameters of atherogenicity (27); since LDL modified by platelet-conditioned medium affects both macrophages and platelets, it could therefore be regarded as possessing atherogenic properties.

Platelets are found in abundance in the area of the atherosclerotic plaque; thus LDL modified by platelet-conditioned medium may be formed in vivo under certain pathological conditions and the platelet-modified LDL may then accelerate the atherosclerotic process. 


\section{References}

1. Brown, M. S. \& Goldstein, J. L. (1983) Lipoprotein metabolism in the macrophage: implications for cholesterol deposition in atherosclerosis. Ann. Rev. Biochem. 52, 223261.

2. Steinberg, D. (1983) Lipoproteins and atherosclerosis: a look back and a look ahead. Arteriosclerosis 3, 281-301.

3. Henriksen, T., Mahoney, E. M. \& Steinberg, D. (1983) Enhanced macrophage degradation of biologically modified low density lipoprotein. Arteriosclerosis 3, 149-159.

4. Goldstein, J. L., Ho, Y. K., Besu, S. K. \& Brown, M. S. (1979) Binding site on macrophage that mediates uptake and degradation of acetylated low-density lipoprotein, producing massive cholesterol deposition. Proc. Natl. Acad. Sci. USA 76, 333-337.

5. Weksler, B. B. \& Nachman, R. L. (1981) Platelets and atherosclerosis. Am. J. Med. 71, 331-333.

6. Aviram, M. \& Brook, J. G. (1987) Platelet activation by plasma lipoproteins. Prog. Cardiovasc. Dis. 30, 61-72.

7. Kruth, H. S. (1985) Platelet-mediated cholesterol accumulation in cultured aortic smooth muscle cells. Science (Wash. D. C.) $227,1243-1245$

8. Aviram, M. (1987) Platelet-modified low density lipoprotein: studies in normal subjects and in patients with homozygous familial hypercholesterolemia. Clin. Biochem. 20, 91-95.

9. Aviram, M. (1983) Plasma lipoprotein separation by discontinuous density gradient ultracentrifugation in hyperlipoproteinemic pàtients. Biochem. Med. 30, 111-118.

10. Bradford, M. (1976) A rapid and sensitive method for the quantitation of microgram quantities of protein utilizing the principle of protein dye binding. Anal. Biochem. 72, $248-254$.

11. Chlamori, N. \& Henry, R. J. (1959) Study of the ferric chloride method for determination of total cholesterol and cholesterol ester. Am. J. Clin. Pathol. 31, 305-309.

12. Basu, S. K., Goldstein, J. L., Anderson, R. G. W. \& Brown, M. S. (1976) Degradation of cationized low density lipoprotein and regulation of cholesterol metabolism in homozygous familial hypercholesterolemic fibroblasts. Proc. Natl. Acad. Sci. USA 73, 3178-3182.

13. Bilhelmer, D. W., Eisenberg, S. \& Levy, R. I. (1972) The metabolism of very low density lipoprotein protein. I. Preliminary in vitro and in vivo observations. Biochim. Biophys. Acta 260, 212-221.

14. Born, G. V. R. (1969) Aggregation of blood platelets by adenosine diphosphate and its reversal. Nature (Lond.) 194, 927-930.
15. Edelson, P. J. \& Cohn, J. A. (1976) Purification and cultivation of monocytes and macrophages. In: In Vitro Methods in Cell-Mediated and Tumor Immunity (Bloom, B. R. \& David, Y. R., eds.) Academic Press, New York. pp. 333340.

16. Goldstein, J. L., Dana, S. E. \& Brown, M. S. (1974) Esterification of low density lipoprotein cholesterol in human fibroblasts and its absence in homozygous familial hypercholesterolemia. Proc. Natl. Acad. Sci. USA 71, 4288-4292.

17. Koo, C., Wernette-Hammond, M. G. \& Innerarity, T. L. (1986) Uptake of canine B-VLDL by mouse peritoneal macrophages is mediated by a low density lipoprotein receptor. J. Biol. Chem. 261, 11194-11207.

18. Basu, S. K., Brown, M. S. \& Goldstein, J. L. (1979) Degradation of low density lipoprotein/dextran sulfate complexes associated with deposition of cholesterol esters in mouse macrophages. J. Biol. Chem. 254, 7141-7146.

19. Fogelman, A. M., Schecter, I., Seager, J., Hokam, M., Child, J. S. \& Edwards, P. A. (1980) Malondialdehyde alteration of low-density lipoproteins leads to cholesterol ester accumulation in human monocytes macrophages. Proc. Natl. Acad. Sci. USA 77, 2214-2218.

20. Nagelkerks, J. F., Havekes, L., van Hinsbergh, V. W. M. \& van Berkel, T. J. C. (1984) In vivo catabolism of biologically modified LDL. Arteriosclerosis 4, 256-264.

21. Sanberg, H., Anderssen, L. O. \& Hoglund, S. (1982) Isolation and characterization of lipid-protein particles containing platelet factor 3 released from human platelets. Biochem. J. 203, 303-311.

22. George, J. V., Pickett, E. B. \& Heinz, R. (1986) Platelet membrane microparticles in blood bank fresh frozen plasma and cryoprecipitate. Blood 68, 307-309.

23. Aviram, M., Maor, I., Rosenblat, M., Dankner, G. \& Brook, J. G. (1988) Platelet modified lipoproteins induced by thrombin: effect of whole blood and plasma. Israel $\mathrm{J}$. Med. Sci. 24, 193-200.

24. Phillips, D. R., Arnold K. \& Innerarity, T. L. (1985) Platelet secretory products inhibit lipoprotein metabolism in macrophages. Nature (Lond.) 316, 746-748.

25. Scanu, A. M., Byrne, R. G. \& Edelstein, C. (1984) Proteolytic events affecting plasma apolipoproteins at the co- and post-translational levels and after maturation. J. Lipid. Res. 25, 1593-1602.

26. Ho, Y. K., Brown, M. S. \& Goldstein, J. L. (1980) Hydrolysis and excretion of cytoplasmic cholesterol esters by macrophages: stimulation by high density lipoprotein and other agents. J. Lipid Res. 21, 391-399.

27. Ross, R. (1986) The pathogenesis of atherosclerosis: an update. N. Engl. J. Med. 314, 488-500.

Michael Aviram D. Sc.

Lipid Research Laboratory

Rambam Medical Center

Haifa, Israel 